\title{
Studies on pyrolysis of Nomex polyaramid fibers
}

(Journal of Analytical and Applied Pyrolysis 58-59, 105-115, 2001)

\author{
S. Villar-Rodil, A. Martínez-Alonso and J.M.D. Tascón \\ Instituto Nacional del Carbón, CSIC, Apartado 73,33080 Oviedo, Spain
}

\begin{abstract}
The pyrolysis behavior of Nomex [poly ( $m$-phenylene isophtalamide)] fibers under argon was studied using thermoanalytical and DRIFTS methods to get direct information on the progressive changes undergone by the solid material and its carbon fiber residues. Simultaneous Thermogravimetry (TG)-Differential Thermal Analysis (DTA) measurements were carried out in a thermobalance in order to establish the different steps in the thermal degradation of Nomex. Samples pyrolyzed to various carefully controlled extents were prepared in the same thermobalance by heating under the same conditions to different temperatures selected as a function of the TG/DTA results. Diffuse Reflectance Infrared Fourier Transform Spectroscopy (DRIFTS) spectra of all samples were obtained in order to follow changes in chemical composition along the pyrolysis process. Rupture of hydrogen bonds takes place in the $300-400{ }^{\circ} \mathrm{C}$ interval, being followed by a complex thermal event involving two weight loss steps and three endothermal DTA peaks. An intermediate aryl nitrile forms from heterolytic decomposition of Nomex above $433^{\circ} \mathrm{C}$ and decomposes totally at $698^{\circ} \mathrm{C}$. From $473^{\circ} \mathrm{C}$ on, the DRIFTS spectra evidence a drop in intensity of amide bands in parallel with increases in primary amine and carbonxyl groups. Total disappearance of amide bands $\left(607^{\circ} \mathrm{C}\right)$ is followed by a DTA exotherm at $627^{\circ} \mathrm{C}$, attributed to condensation reactions. Accordingly, $\mathrm{C}=\mathrm{C}$ skeletal vibrations in
\end{abstract}


polyaromatic networks develop confirming the occurrence of a progressive loss of heteroatoms and an increase in aromaticity.

Keywords: aramid fibers; DRIFTS; DTA; Nomex; TG; thermal decomposition.

\section{Introduction}

Activated carbon fibers (ACF) are usually prepared from low-cristallinity feedstocks such as polyacrilonitrile, viscose rayon, kapton polyimide, phenolic resins, and coal tar pitch-derived carbon fibers [1,2], as well as cloths or felts made from them [3,4]. The properties of the resulting carbonaceous adsorbents depend of the nature of the raw material used, the nature of the activating agent and the conditions of the pyrolysis and activation processes [5]. In fact, the operational parameters in the pyrolysis step have a marked influence in the ensuing activation and further in the quality of the final product [5,6]. An important factor influencing surface and structural properties of ACF is the temperature of polymer carbonization prior to physical activation [7]. Consequently, knowledge of phenomena involved in this pyrolysis step deserves much interest as it can contribute to optimum selection of the pyrolysis/activation conditions.

Polyaramid fibers constitute suitable precursors for the preparation of ACF by pyrolysis followed by physical activation with oxidizing gases. Recent work has shown that $\operatorname{Kevlar}^{\circledR}$ [poly ( $p$-phenylene terephtalamide), henceforth designated as Kevlar] [8] and Nomex ${ }^{\circledR}$ [poly ( $m$-phenylene isophtalamide), henceforth designated as Nomex] $[9,10]$ give rise to ACF that are very attractive as sorbents due to their narrow pore size distribution.

Previous work from our laboratory allowed us to establish the nature of changes taking place in Kevlar during thermal decomposition of this aramid fiber. Thus, formation of an intermediate aryl nitrile species was detected, and rupture of the amide 
(decomposition of amide groups by $\mathrm{C}=\mathrm{O}$ and $\mathrm{C}-\mathrm{N}$ bond cleavage) was found to occur within a narrow temperature interval [11]. This added some insight to existing knowledge since most of previous research on Kevlar pyrolysis had been concerned with caracterizing volatile products formed in its degradation.

As with Kevlar, previous work on the pyrolysis of Nomex has mainly dealt with identifying the evolved volatile products [12]. Khanna et al [13] indicated that volatile degradation products contain one or two aromatic rings whose substituent groups are essentially amino, nitrile, carboxyl and phenyl. Brown and Power [14] studied the variation in the composition of volatiles at pyrolysis temperature in the $300-700^{\circ} \mathrm{C}$ range. The nature of evolved products provided evidence for the occurrence of both homolytic and heterolytic ruptures of the amide unit, the first type being predominant at high temperatures and the second one at low temperatures. The degradation begins by reactions involving homolytic cleavage of the $\mathrm{HN}-\mathrm{CO}$ bond and aromatic bonds, with $-\mathrm{NH}$ subsequent protonation and dehydration of intermediate end groups as well as heterolytic cleavage of the NH-CO bond [14].

These studies based on analyzing the volatile descomposition products provide interesting indirect information on the chemistry involved in Nomex pyrolysis. However, direct information on the progressive changes undergone by the solid material is not currently available. Only in a work from Yoon et al. [15] the elemental composition of the solid residue after pyrolysis under different conditions was determined.

The main objective of this study is to follow the evolution of functionalities present in Nomex during pyrolysis, the knowledge of which will allow rational selection of optimal conditions for the pyrolysis treatment prior to ulterior activation of the resulting char. In this work a methodology similar to that used previously with Kevlar [11] has been applied to Nomex. It combines thermal analysis and infrared spectroscopic data. These 
results are expected to deserve interest in the general field of thermal stability of Nomex fibers, as they are used as a fire-resistant material for protective clothing or in fire blocking materials for aircrafts

\section{Experimental}

The starting material was commercial polymer Nomex ${ }^{\circledR}$ T450 2.2 dtex. This product is manufactured by DuPont and its chemical composition is poly ( $m$-phenylene isophtalamide). The equilibrium moisture of Nomex virgin fibers was determined from their weight loss after heating for $70 \mathrm{~min}$ at $110^{\circ} \mathrm{C}$ and cooling in a dessicator. An average value of 6.5 wt. $\%$ of moisture was obtained. Elemental analysis of the starting material was carried out in a LECO CHNS-932 microanalysis apparatus with a LECO VTF-900 accessory for oxygen. The elemental analysis of virgin Nomex fibers, reported on dry basis, gave $71.2 \% \mathrm{C} ; 3.9 \% \mathrm{H} ; 9.7 \% \mathrm{~N} ; 15.5 \% \mathrm{O}$.

Simultaneous Thermogravimetry (TG) /Differential Thermal Analysis (DTA) experiments were carried out in a Stanton-Redcroft STA-1500 thermogravimetric analyzer provided with a Plus-V software. As received fibers, without drying, were used in all thermal treatments. Samples $(\sim 10 \mathrm{mg})$ were placed in Pt crucibles $5 \mathrm{~mm}$ in diameter and 5 $\mathrm{mm}$ in height. An argon (99.99990\% pure by volume) constant flow of $50 \mathrm{~cm}^{3} \mathrm{~min}^{-1}$ at atmospheric pressure was used. $\alpha$-Alumina was the reference material for DTA measurements. Temperatures were measured with $\mathrm{Pt} / \mathrm{Rh}$ thermocouples placed at the bottom of the Pt crucibles, in contact with them. A heating rate of $10^{\circ} \mathrm{C} \mathrm{min}^{-1}$ has been chosen. Samples pyrolyzed to various carefully controlled extents were prepared in the same thermobalance under the same conditions, by heating at $10^{\circ} \mathrm{C} \min ^{-1}$ to different selected temperatures, followed by rapid cooling to room temperature. 
Diffuse Reflectance Infrared Fourier Transform Spectroscopy (DRIFTS) spectra of all samples were obtained in a Nicolet Magna IR560 spectrometer using a high sensitivity MCT/A detector. Spectra shown are the result of coadding 200 interferograms obtained at a resolution of $4 \mathrm{~cm}^{-1}$. All samples, fresh and pyrolyzed, were cold-ground at $-196^{\circ} \mathrm{C}$ in a mixer mill used in combination with a cooling attachment in which liquid nitrogen was the coolant. Then, they were kept in a desiccator, avoiding direct exposure to sunlight (Nomex has a strong absorption in the UV region which may cause its photochemical degradation) [16].

\section{Results and Discussion}

\subsection{Thermal Analysis Studies}

Figure 1 shows TG, DTG and DTA curves obtained during Nomex pyrolysis under argon. The TG curve first exhibits a weight loss ascribable to release of adsorbed moisture that extends from room temperature to $105^{\circ} \mathrm{C}$, being accompanied by a strong endothermal effect with DTA minimum at $60^{\circ} \mathrm{C}$ that coincides with a minimum in the DTG curve.

No further changes in mass or energy occur between 105 and $270^{\circ} \mathrm{C}$, where a slight weight loss of approximately $1 \%$ takes place, accompanied by a small DTA peak with an endothermal minimum centered at $317^{\circ} \mathrm{C}$ coincident with the DTG minimum. This could be related to breaking of hydrogen bonds between polyaramide chains. Such a process would explain the change in crystallinity found $[17,18]$ following moderate 


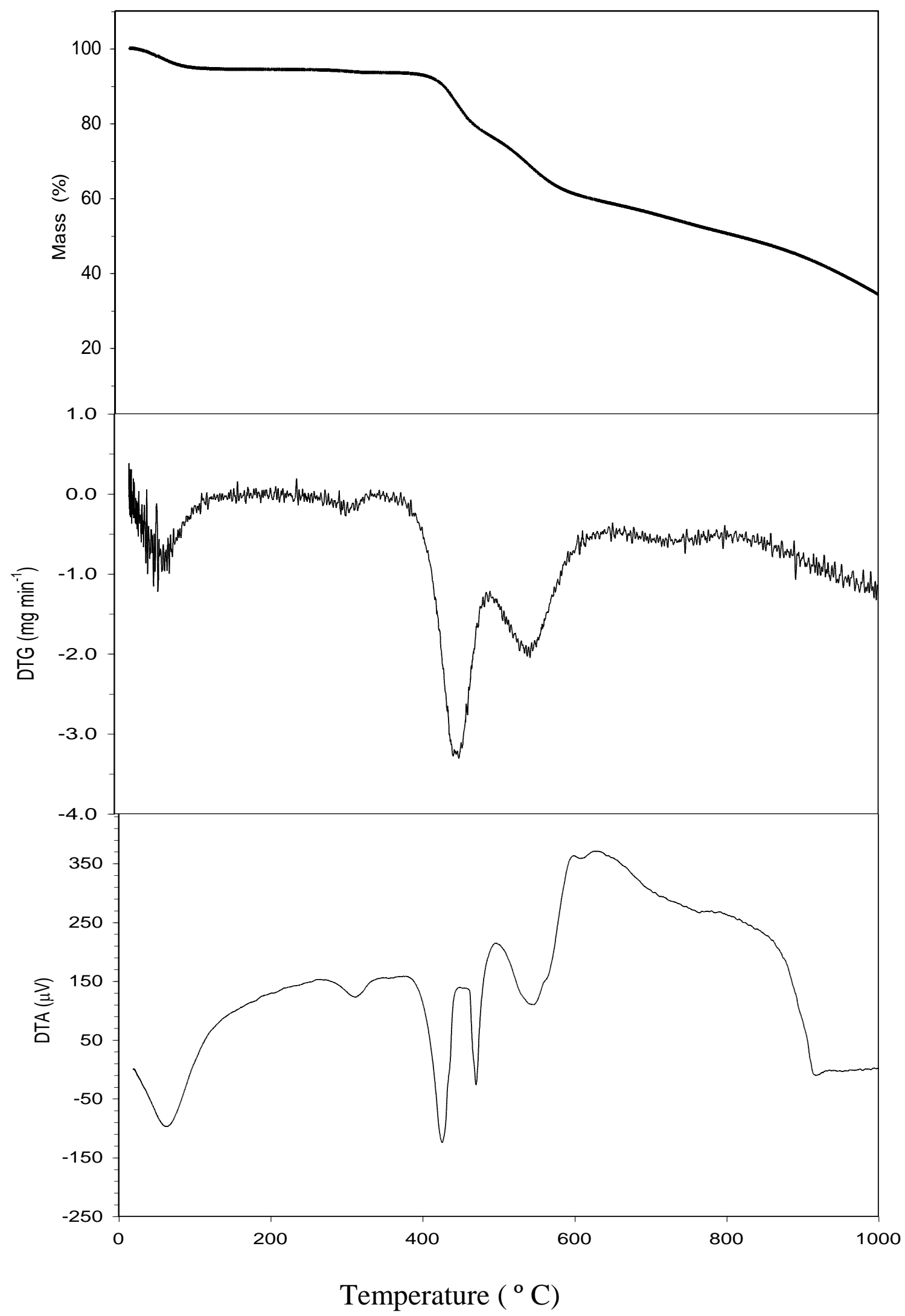

Figure 1. TG, DTG and DTA curves for Nomex pyrolysis under argon. 
thermal treatments. It could also account for the change in color observed when white fresh fibers acquire a pale yellow tonality upon heating to $360^{\circ} \mathrm{C}$. If hydrogen bonds break between those two stages, although they will form again when the sample is cooled to room temperature they will not be forced to form in such an ordered way as they are during fiber processing. If the number of hydrogen bonds diminishes significantly then the lowering in the wavelength absorption of the polymer from UV (white fiber) to VIS (yellow fiber) can be explained taking into account that the non-bonding pair of oxygen in the cromophoric carbonyl group takes part in the hydrogen bonding, thus raising the energy of $n \rightarrow \pi^{*}$ excitation by an amount roughly equal to the strength of the hydrogen bond and producing an hypsochromic shift which can be as much as $200 \mathrm{~nm}$.

A temperature of $420^{\circ} \mathrm{C}$ is the onset of a further weight loss step that becomes significant above $430{ }^{\circ} \mathrm{C}$ and ends at approximately $487^{\circ} \mathrm{C}$ where a new weight loss step begins to end at $607^{\circ} \mathrm{C}$. This two-step weight loss is accompanied by three well-defined endothermal DTA peaks with minima at 427 (centered at the middle of the first TG step), 471 (between both steps) and $550^{\circ} \mathrm{C}$ (second step). The two weight loss steps in the degradation of Nomex may be related to previous results of Kalashnik et al. [19] in which the predominating processes in the thermal degradation of aramids differ before and after $\sim 480^{\circ} \mathrm{C}$, being respectively heterolytic and homolytic ones. Globally, this thermal event is considerably more complex than that found for Kevlar studied under equivalent conditions [11].

The DTA minimum at $550^{\circ} \mathrm{C}$ is followed by a sudden change in sign of the thermal effect, a broad DTA exotherm appearing at $627^{\circ} \mathrm{C}$. This coincides with a decrease in the slope of the TG curve, and could be related to condensation reactions yielding polyaromatic compounds. The observed shift in the VIS absorption to lower wavenumbers (from bright yellow at $400{ }^{\circ} \mathrm{C}$ to black attained at about $530^{\circ} \mathrm{C}$ ) is a good indication of 
the increase in aromaticity which takes place parallel to the disappearence of functional groups.

Further on, no plateau is attained even at $1000^{\circ} \mathrm{C}$, the continuous small weight loss in this interval being accompanied by a broad exotherm extending all over this temperature range. The residue at $1000^{\circ} \mathrm{C}$ is approx. $36 \mathrm{wt} . \%$ in dry basis.

\subsection{DRIFTS study of the $25-400^{\circ} \mathrm{C}$ range}

DRIFTS spectra of Nomex, fresh and heated to $360^{\circ} \mathrm{C}$, are presented in Figure 2. As indicated above, poly ( $m$-phenylene isophtalamide) is the base polymer for this aramid fiber. According to this chemical composition, the structure of this polymer and the ensuing study of the variation of band intensities during the pyrolysis process, the following band assignments can be made: $3307 \mathrm{~cm}^{-1}$, N-H stretching vibrations in a secondary amide in trans form with a bonded hydrogen; $3077 \mathrm{~cm}^{-1}$, C-H stretching vibrations in an unsaturated compound; $1667 \mathrm{~cm}^{-1}$, amide $\mathrm{C}=\mathrm{O}$ stretching (usually designated as amide I band) for hydrogen-bonded amide groups; $1610 \mathrm{~cm}^{-1}, \mathrm{C}=\mathrm{C}$ stretching vibrations of aromatic ring; $1545 \mathrm{~cm}^{-1}, \mathrm{~N}-\mathrm{H}$ deformation and $\mathrm{C}-\mathrm{N}$ stretching coupled modes of the C-N-H group (also known as amide II band); $1325 \mathrm{~cm}^{-1}$, aromatic C$\mathrm{N}$ stretching; $1248 \mathrm{~cm}^{-1}$, coupling of C-N stretching and $\mathrm{N}-\mathrm{H}$ bending (amide III band); $784 \mathrm{~cm}^{-1}$ and $687 \mathrm{~cm}^{-1}$, out-of-plane $\mathrm{C}-\mathrm{H}$ vibrations of one and three adjacent hydrogens in a meta-substituted aromatic ring; $721 \mathrm{~cm}^{-1}, \mathrm{~N}-\mathrm{H}$ deformation mode.

Assignation of the remaining bands is less clear. A very weak absorption band appears at $3153 \mathrm{~cm}^{-1}$. Bands of secondary amides around $3100 \mathrm{~cm}^{-1}$ have been explained as due to the Fermi resonance of the N-H stretching with the overtone of the amide II band in trans-amides and due to the Fermi resonance of $\mathrm{C}=\mathrm{O}$ stretching and $\mathrm{N}-\mathrm{H}$ in-plane 
bending in cis-amides. The former could be the case in Nomex, as the intensity of this band during the thermal treatment drops comparably to those of the bands assigned to the amide group. Finally, inorganic impurities have not been detected in the DRIFTS spectrum. In fact, Nomex leaves no residue (no ash) upon thermal treatments in air at high temperature $\left(815^{\circ} \mathrm{C}\right)$

The DRIFTS spectrum obtained after heating Nomex to $360^{\circ} \mathrm{C}$ shows the same absorption bands as for fresh Nomex. However, the fact that the absorption band corresponding to $\mathrm{N}-\mathrm{H}$ stretching becomes broader can be related to the disappearance of hydrogen bonds already mentioned above. The hydrogen bonds in fresh Nomex shift the $\mathrm{N}-\mathrm{H}$ stretching band to lower wavenumbers relative to the band in the heated sample, where the hydrogen bonds have broken. Then, as the quantity of hydrogen bonds diminishes, the peak broadens to higher frequencies. Nevertheless, this trend is not so obvious in the $\mathrm{C}=\mathrm{O}$ band.

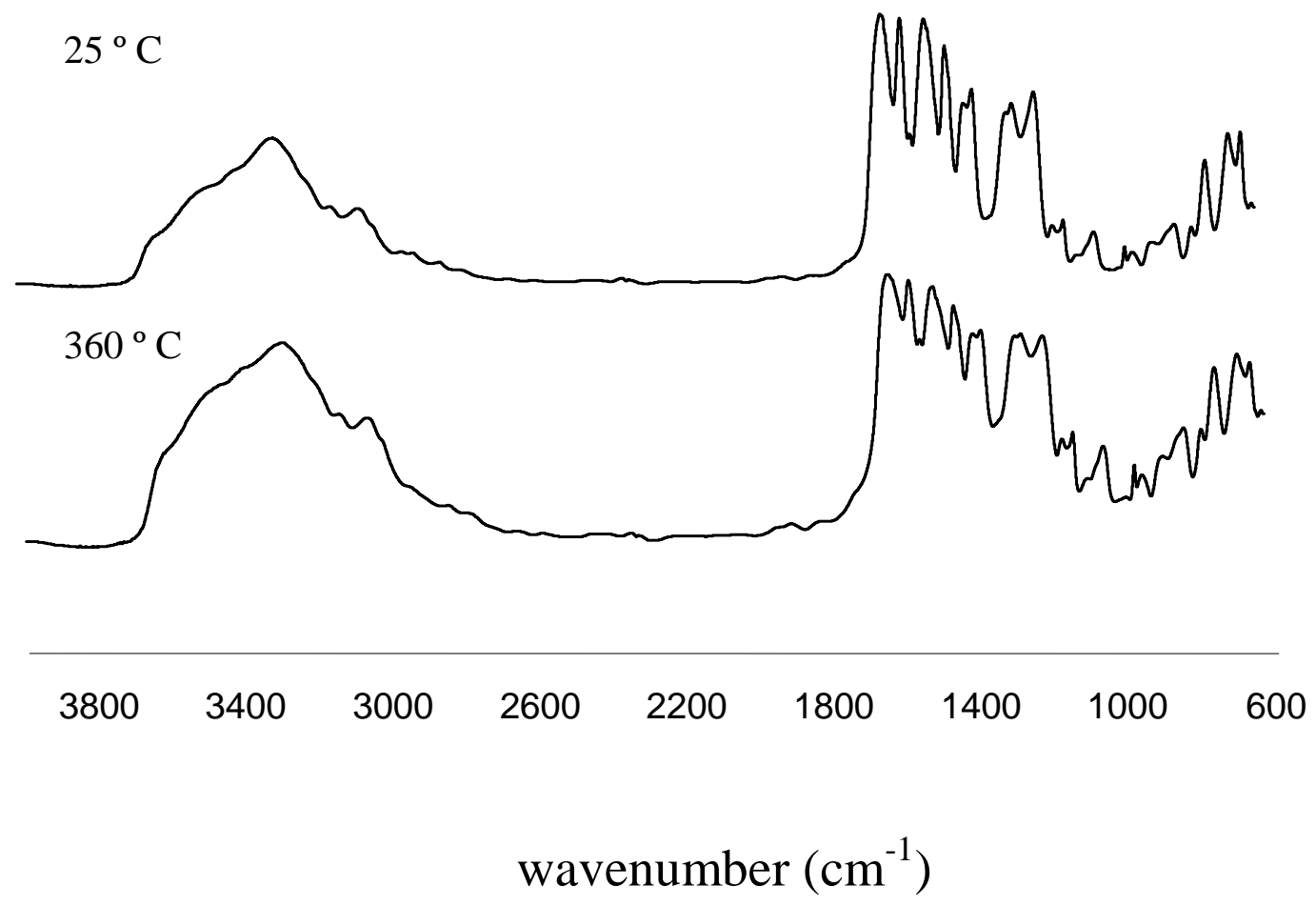

Figure 2. DRIFTS spectra of Nomex, fresh and heated to $360{ }^{\circ} \mathrm{C}$. 


\subsection{DRIFTS study of the $400-487^{\circ} \mathrm{C}$ range}

Figure 3 shows DRIFTS spectra of several Nomex low-temperature pyrolysis products corresponding to the first step observed in the TGA curve. In the DRIFTS spectrum corresponding to a treatment at $433^{\circ} \mathrm{C}$ an absorption band with a very weak intensity appears at $2230 \mathrm{~cm}^{-1}$ and becomes significant at $463^{\circ} \mathrm{C}$. It can be assigned to the stretching vibration of $\mathrm{C} \equiv \mathrm{N}$, more specifically in an aryl nitrile. This nitrile would be formed from heterolytic decomposition of Nomex [19]. There is a parallelism with the case of Kevlar, where a band at $2224 \mathrm{~cm}^{-1}$ ascribed to an aryl nitrile began to develop above 523 ${ }^{\circ} \mathrm{C}[11]$.

From then on, a significant change is evident in the DRIFTS spectra corresponding to samples treated at higher temperatures. A drop in absorption is observed in all the bands ascribed to the amide group without any shift except the progressive broadening of the $\mathrm{N}$ $\mathrm{H}$ peak to higher wavelenghts. The relative amount of end groups increases as reaction progresses, so shoulders which already appeared in the starting product $(3600,3480,3370$ $\left.\mathrm{cm}^{-1}\right)$ corresponding to carboxylic $\left(3500-3560 \mathrm{~cm}^{-1}\right.$ for $\mathrm{O}-\mathrm{H}$ stretching) end groups and primary amine $\left(\sim 3400-3500 \mathrm{~cm}^{-1}\right.$ for free ${ }^{1} \mathrm{~N}-\mathrm{H}$ stretching; 3180-3350 for bonded $\left.\mathrm{N}-\mathrm{H}\right)$ grow in relation to the peak centered at $3307 \mathrm{~cm}^{-1}$ corresponding to secondary amide. In the spectrum corresponding to a temperature of $473^{\circ} \mathrm{C}$ a peak centered at $3307 \mathrm{~cm}^{-1}$ and the nearest shoulder at $3370 \mathrm{~cm}^{-1}$ are almost equal in height yielding a bad-defined peak. Also in this spectrum, a peak around $3630 \mathrm{~cm}^{-1}$, which had already appeared at $452^{\circ} \mathrm{C}$, becomes significant. Let us remind here the higher thermal stability of Kevlar, whose amide groups decomposed at higher temperatures over a narrow temperature interval [11]. 


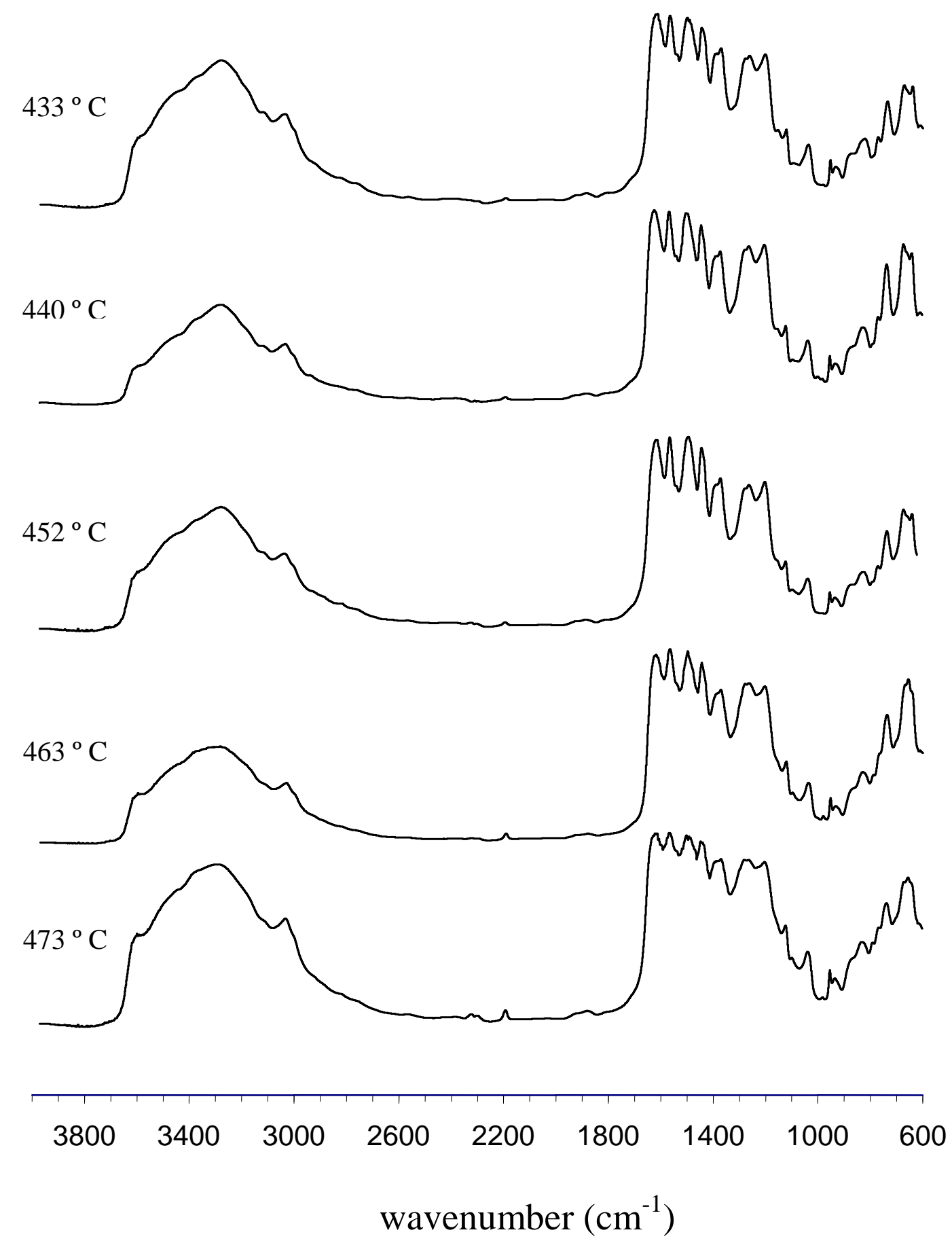

Figure 3. DRIFTS spectra of Nomex solid decomposition products in the $433-478{ }^{\circ} \mathrm{C}$ range. 
DRIFTS spectra of several Nomex pyrolysis products corresponding to the second step observed in the TGA curve are presented in Figure 4. There are no major changes in this temperature range as compared to the previous one. The same trend is followed: the absorption bands ascribed to amide group suffer a gradual decrease in intensity with increasing temperature of treatment. Now the main peak in the $4000-3000 \mathrm{~cm}^{-1}$ spectral region becomes a well-defined peak centered at $3370 \mathrm{~cm}^{-1}$, maybe related to a mixture of free and bonded N-H amine bond stretching vibration (hydrogen bonds can be formed as the sample is cooled to room temperature). Well-defined peaks at $600^{\circ} \mathrm{C}$ can be explained as a mixture of those due to a $m$-benzenediamine and to benzonitrile.

\subsection{DRIFTS study at temperatures higher than $607^{\circ} C$.}

Figure 5 shows DRIFTS spectra of Nomex pyrolysis products corresponding to this temperature range. When the treatment temperature exceeds $607^{\circ} \mathrm{C}$ the DRIFTS spectra are entirely modified, and the absorption bands of amide groups completely disappear. In this temperature range, the $2230 \mathrm{~cm}^{-1}$ band intensity $(\mathrm{C} \equiv \mathrm{N})$ decreases due to the decomposition of the intermediate aryl cyanide formed at lower temperatures. At $689^{\circ}$ $\mathrm{C}$ it has almost disappeared.

A band arises at $1620 \mathrm{~cm}^{-1}$ which can be ascribed to $\mathrm{C}=\mathrm{C}$ skeletal vibrations in polynuclear aromatic hydrocarbons or aromatic compounds substituted by functional groups with heteroatoms. Probably both of them are present in the product, giving rise to a mixed band. Also, bands below $900 \mathrm{~cm}^{-1}$ can be ascribed to out-of-plane C-H vibrations of adjacent hydrogen atoms in substituted polynuclear aromatic compounds. This confirms 


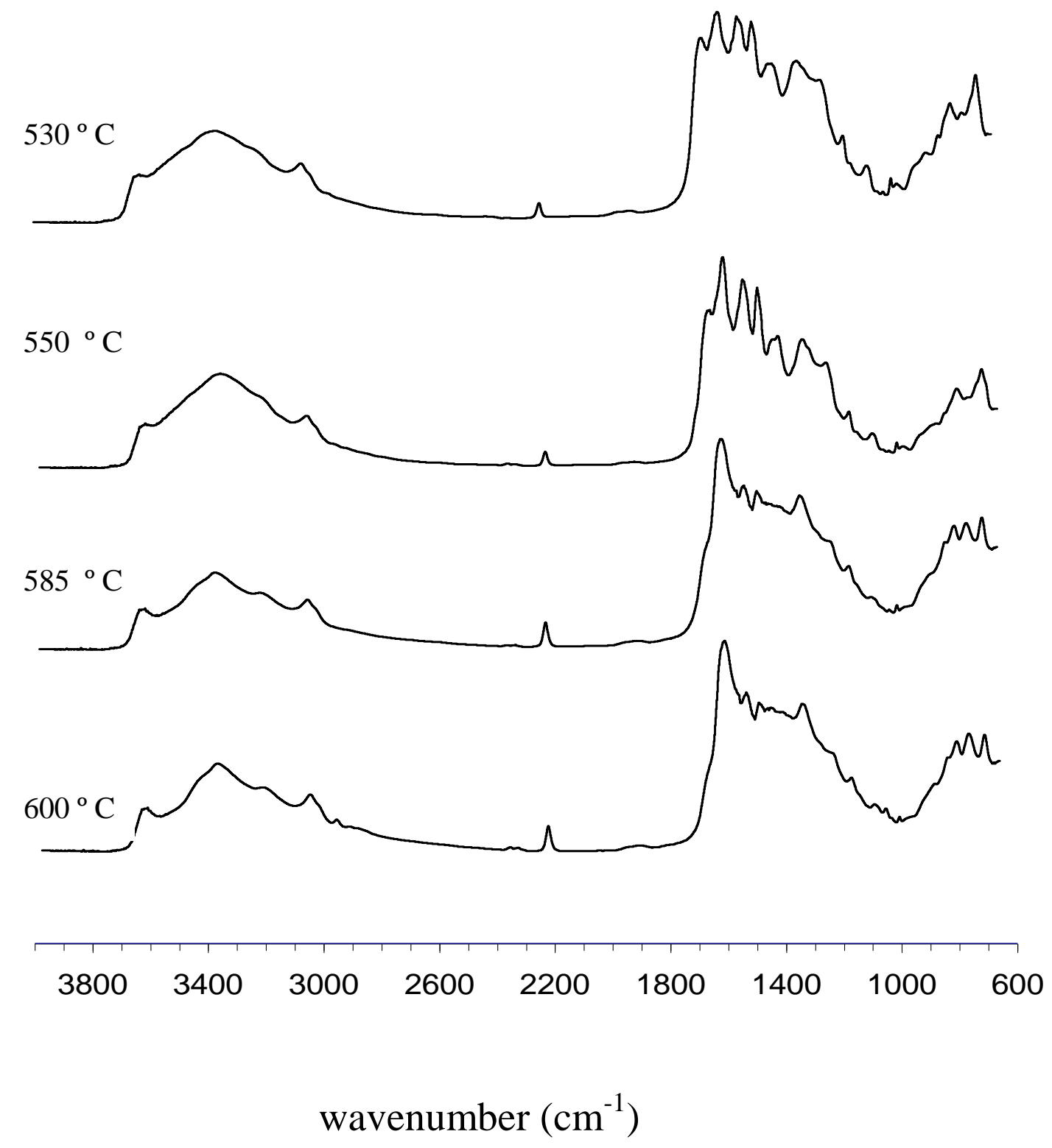

Figure 4. DRIFTS spectra of Nomex solid decomposition products in the $478-600{ }^{\circ} \mathrm{C}$ range. 

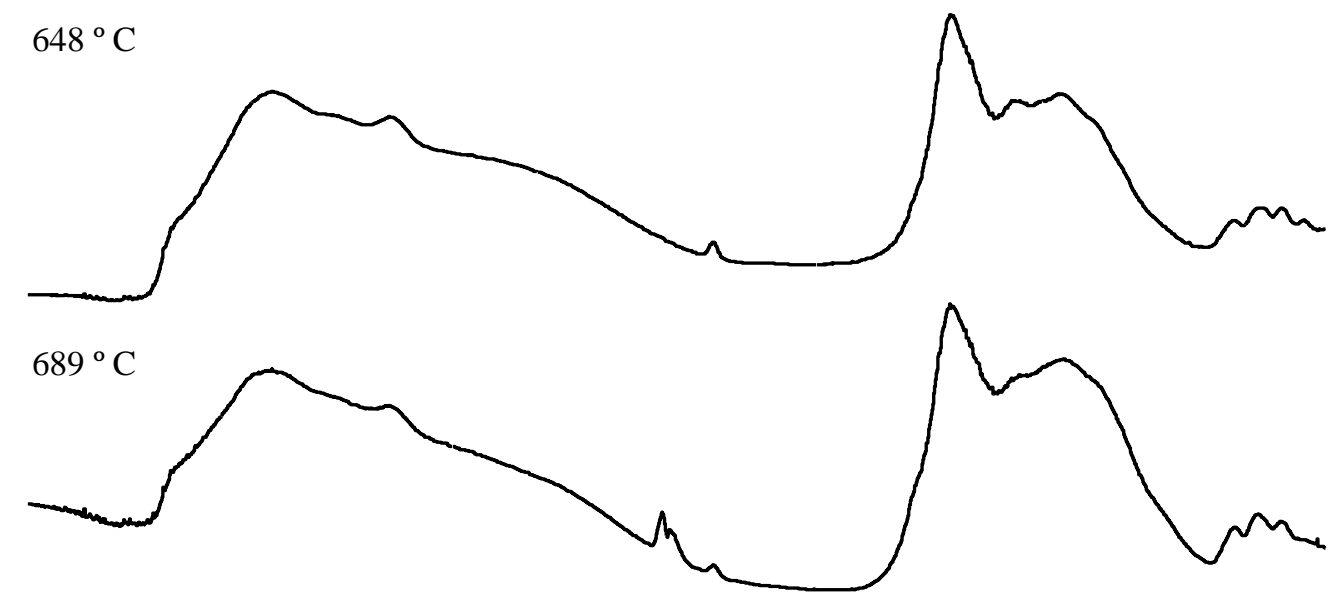

$749^{\circ} \mathrm{C}$
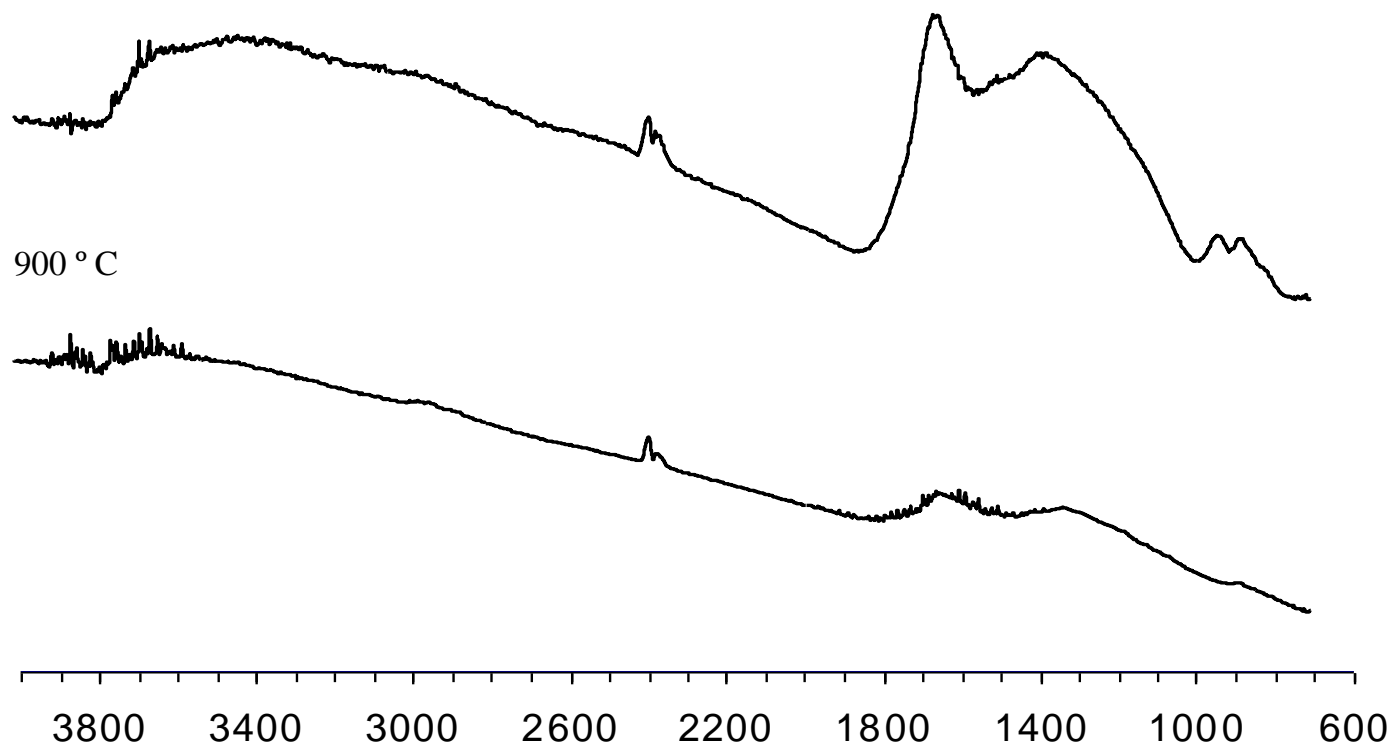

wavenumber $\left(\mathrm{cm}^{-1}\right)$

Figure 5. DRIFTS spectra of solid residues from Nomex heated to temperatures higher than $600^{\circ} \mathrm{C}$. 
the occurrence in this final pyrolysis step of polycondensation reactions leading to increasing aromatization of the carbon fibers residue.

\section{Conclusions}

The TG-DTA-DRIFTS combination of techniques used in this work is suitable to identify changes taking place in Nomex fibers during pyrolysis. After moisture release, Nomex undergoes changes reflected in TG, DTG and DTA curves near $317^{\circ} \mathrm{C}$, ascribable to rupture of hydrogen bonds, which are only accompanied by broadening of $\mathrm{N}-\mathrm{H}$ streching band in the DRIFTS spectrum of Nomex pyrolyzed at $360^{\circ} \mathrm{C}$.

Further on, a two-step weight loss $\left(400-487^{\circ} \mathrm{C}\right.$ and $\left.487-607^{\circ} \mathrm{C}\right)$ takes place, being accompanied by three well-defined DTA endothermal peaks centered at 447,471 and $550^{\circ}$ C. DRIFTS Spectra obtained at $433-463{ }^{\circ} \mathrm{C}$ evidence formation of an aryl nitrile that would form from heterolytic decomposition of Nomex. From $473^{\circ} \mathrm{C}$ on, the spectra evidence a neat drop in the intensities of all amide group bands along with increases in primary amine and carbonyl group bands. In the $487-607^{\circ} \mathrm{C}$ interval, corresponding to the second major weight loss step, an equivalent trend is followed in DRIFTS spectra: gradual loss of amine groups and growth of a well-defined peak centered at $3370 \mathrm{~cm}^{-1}$, attributed to a mixture of free and bonded $\mathrm{N}-\mathrm{H}$ stretching vibration of the amine group.

The DTA endothermal peak at $550^{\circ} \mathrm{C}$ is followed by a sudden change in sign of the thermal effect, with a broad DTA exothermal band with maximum at $627^{\circ} \mathrm{C}$ that coincides with a decrease in the slope of the TG curve. This can be attributed to condensation reactions yielding polyaromatic compounds. Accordingly, above $607^{\circ} \mathrm{C}$, the DRIFTS spectra show complete disappearance of amide bonds and decrease of the aryl nitrile band, that disappears at $689^{\circ} \mathrm{C}$. At the same time a band appears at $1620 \mathrm{~cm}^{-1}$, 
being ascribable to $\mathrm{C}=\mathrm{C}$ skeletal vibrations in polynuclear aromatic hydrocarbons or aromatic hydrocarbons substituted by functional groups with heteroatoms. Bands typical for out-of-plane C-H vibrations in substituted polynuclear aromatic hydrocarbons confirm the occurrence of condensation reactions leading to a progressively condensed carbonaceous material.

\section{Acknowledgements}

Financial support from CICYT (project 1FD1997-1915) is gratefully acknowledged. We also acknowledge a predoctoral fellowship from the Spanish Ministry of Education awarded to S.V.R. Thanks are given to Mr. Javier Fernandez (Du Pont Asturias) for providing the fresh Nomex sample.

\section{References}

[1] J. Alcañiz-Monge, D. Cazorla-Amorós, A. Linares-Solano, S. Yoshida and A. Oya, Carbon, 32 (1994) 1277-1283.

[2] D. Cazorla Amorós, J. Alcañiz-Monge, and A. Linares-Solano, Langmuir, 12 (1996) 2820-2824.

[3] C. Brasquet, B. Rousseau, H. Estrade-Szwarckopf and P. Le Cloirec, Carbon, 38 (2000) 407-422.

[4] A.C. Pastor, F. Rodríguez-Reinoso, H. Marsh and M.A. Martínez, Carbon, 37 (1999) 1275-1283.

[5] R.C. Bansal, J.B. Donnet and F. Stoeckli, Active Carbon, Marcel Dekker, New York, 1988.

[6] D.M. Mackay and P.V. Roberts, Carbon, 10 (1982) 105-111. 
[7] I.N. Ermolenko, I.P. Lyubliner and N.V. Gulko, Chemically Modified Carbon Fibers and their Applications, VCH, Weinheim, Germany, 1990.

[8] A. Martínez-Alonso, M. Jamond, M.A. Montes-Morán and J.M.D. Tascón, Microporous Materials, 11 (1997) 303-311.

[9] M.C. Blanco López, A. Martínez-Alonso and J.M.D. Tascón, Microporous and Mesoporous Materials, 34 (2000) 171-179.

[10] M.C. Blanco López, A. Martínez-Alonso and J.M.D. Tascón, Carbon, in press.

[11] M.E.G. Mosquera, M. Jamond, A. Martínez-Alonso and J.M.D. Tascón, Chem. Mater., 6 (1994) 1918-1924.

[12] J.R. Brown and A.J. Power, J. Polym. Degrad. Stab. 4 (1982) 379-392.

[13] E.M. Pearce, J.S. Smith, D.T. Burkitt, H. Njuguna, D. Hinderlang and B.D. Forman, J. Polym. Sci., Polym. Chem. Ed., 19 (1981) 2817-2821

[14] J.R. Brown and A.J. Power, J. Polym. Degrad. Stab., 4 (1982) 379-392.

[15] S.H. Yoon, B.C. Kim, I. Korai and I. Mochida, 22 Biennial Conference on Carbon. Extended Abstracts and Program, San Diego, CA, 1995, pp. 218-219.

[16] L.E. Hamilton, B.M. Gatewood and P.M.A. Sherwood, Textile Chemist \& Colorist, 26 (1994) 39-45.

[17] M. G. Dobb, in W. Watt and B. V. Perov (Ed.), Srong Fibers, North -Holland, Amsterdam, 1985, p. 693.

[18] A. M. Hindeleh and Sh. M. Abdo, Polymer, 30, 218 (1989).

[19] A. T. Kalashnik, N. P. Panikarova, Ye. U. Dovbii, G. V. Kozhine, V. D. Kalmykova and S. P. Papkov, Polym. Sci. USSR, 19, 2747 (1977). 